\title{
EFFECT OF ASPERGILLUS NIGER STRAIN XF-1 ON SOIL NUTRIENTS AND GROWTH OF AMORPHA FRUTICOSA
}

\author{
WU, Q.-F. ${ }^{1}-\mathrm{HU}, \mathrm{H} .-\mathrm{B} .{ }^{2,3^{*}}-\mathrm{HE}, \mathrm{L} .-\mathrm{M} .{ }^{1}$ \\ ${ }^{I}$ School of Biological and Food Engineering, Anyang Institute of Technology, Anyang, Henan \\ 455000, China \\ ${ }^{2}$ Collaborative Innovation Center of Sustainable Forestry in Southern China of Jiangsu \\ Province, Nanjing Forestry University, 159 Longpan Road, Nanjing, Jiangsu 210037, China \\ ${ }^{3}$ Key Laboratory of Soil and Water Conservation and Ecological Restoration in Jiangsu \\ Province, Nanjing Forestry University, 159 Longpan Road, Nanjing, Jiangsu 210037, China \\ *Corresponding author \\ e-mail:531208831@qq.com
}

(Received $4^{\text {th }}$ Nov 2019; accepted $7^{\text {th }}$ Jul 2020)

\begin{abstract}
In order to reveal the interaction effect between Aspergillus niger (A. niger) and Amorpha fruticosa (A. frusticosa), to guide the large-scale production and cultivation of A. fruticose in ecological restoration, and to promote the greening of rock slope and improve the ecological environment, a study on the effect of fermentation broth with different dilutions of $A$. niger strain XF-1 on soil nutrient elements and the growth of A. fruticosa was conducted by pot experiment in a green house. The results showed that the contents of chlorophyll a, chlorophyll $\mathrm{b}$ and total chlorophyll in the leaves of A. fruticosa significantly increased with the $10^{-2}$ dilution. A. niger strain XF-1 fermentation broth, and the plant height, fresh weight and dry weight of A. fruticosa significantly increased. Whether the condition of planting A. fruticosa or not, the contents of available phosphorus, iron, copper, and zinc in soil by watering were higher in A. niger strain XF-1 fermentation broth than that of control (no watering A. niger strain XF-1 fermentation broth), and the contents of the above-mentioned nutrients by watering with the $10^{-2}$ dilution were the highest in soil in A. niger strain XF-1 fermentation broth, which could significantly promote the growth of A. fruticosa. Therefore, A. niger strain XF-1 has a good growth promotion effect on A. fruticosa.
\end{abstract}

Keywords: Aspergillus niger, nutrient element, growth-promoting, Amorpha fruticosa, weathering

\section{Introduction}

Aspergillus niger (A. niger) can dissolve the elements in rocks and minerals, releasing phosphorus, potassium, calcium, silicon and other elements in a form that is easy to be absorbed by plants (Wu, 2018). Meanwhile, it can also secrete oxalic acid, tartaric acid and citric acid to promote the growth of plants (Wang et al., 2018). It is a good strain used as a biological fertilizer. Zhang Lizhen et al. isolated and screened a strain of $A$. niger from caragana rhizosphere soil from a saline-alkali land, and found that this strain could convert insoluble inorganic phosphorus into available phosphorus nutrients for plants to absorb through metabolism, and improve the effective utilization rate of phosphorus (Zhang et al., 2011). Qian Linzhao found in his study that after adding $A$. niger fermentation broth, the $\mathrm{pH}$ value in the soil was significantly reduced, and the effective $\mathrm{P}$, exchangeable $\mathrm{Ca}, \mathrm{Mg}$ and effective $\mathrm{Fe}, \mathrm{Cu}$ and $\mathrm{Zn}$ in the soil were effectively released in the acidic environment, resulting in a significant increase in the content of nutrient elements in the soil (Qian, 2014). Wang Yanqiu et al. used A. niger Ap-2 strain to produce biophosphorus bacterial fertilizer, and found that the content of available phosphorus in soil increased by $141.94 \%$. The weight of single leaf, the 
proportion of superior tobacco and the internal quality of tobacco leaf were all better than the control (Wang et al., 1993). Li Song et al. found that secondary metabolites of A. niger could promote the growth of potted tomatoes and reduce the incidence of tomato root knot nematode disease (Li et al., 2011). Gong Mingbo et al. inoculated $A$. niger in the corn field experiment, and the corn yield increased by about $15 \%$ compared with the control treatment (Gong et al., 2010). Lu Jing et al. found that the chlorophyll content, photosynthetic rate and the accumulation of carbon assimilation products in wheat leaves were enhanced when 100 times of $A$. niger fermentation broth was irrigated. It also significantly promoted the nitrate reductive activity of wheat leaves and roots $(\mathrm{p}<0.05)$, and the nitrogen metabolism rate, protein content, total phosphorus content of plant tissues in wheat seedlings (up to 61\%) and biomass accumulation in wheat parts above ground all increased significantly (up to $21 \%$ ). After applying $A$. niger fermentation broth diluted 100 times, the available phosphorus content of the soil increased by $122 \%$ during the experiment. The decrease of soil total phosphorus was greater than that of the corresponding control group (Lü et al., 2015). Relevant studies have shown that microorganisms can resist diseases and insect pests, absorb heavy metals, dissolve phosphorus and release potassium, therefore, they can be successfully used in bioremediation, promotion of crop growth and improvement of crop quality.

Amorpha fruticosa (A. fruticosa), also called Shrubby falseindige, is a perennial deciduous shrub, that has a strong vitality, resistance to drought (Yan et al., 2017), resistance to water dipping, resistance to cold, resistance to the sand, resistance to pests, resistance to stress, and resistance to pollution (Cui et al., 2016). It is currently an important plant in the flood control and highway defence in China, and it is also one of the common species of slope greening trees. A. fruticose is a good green fertilizer and animal feed, leaves of which are large and rich in nutrition. At the same time, the root wart of A. fruticose in the part of root plays an important role in soil improvement. When Yang Chuanxing et al. investigated the weathering soil thickness of gangue hill in semi-arid areas, they found that the weathering soil thickness of A. fruticosa was the thickest in the five years old young trees among A. fruticosa, Robinia pseudoacacia, Ulmus pumila and Seabuckthorn. Compared with other tree species, A. fruticose can save $50 \%$ of the cost in the greening of gangue hill. Planting A. fruticose can accelerate the surface weathering of gangue, forming of soil, thus afforestation cost is lower (Yang, 2008).

Plant beneficial rhizospheric microorganisms (PBRMs) are able to colonize the rhizosphere and to improve plant growth, development and nutrient use efficiency by means of a wide variety of mechanisms like organic matter mineralization, biological control against soil-borne pathogens, biological nitrogen fixation, potassium, phosphorous and zinc solubilization and root growth promotion (Meena et al., 2017; Eriola, 2018). The growth promotion effect of $A$. niger $\mathrm{XF}-1$ on A. fruticosa was studied in a green house. We tested the effect of different concentrations of fermentation broth of $A$. niger XF-1 on the growth of $A$. fruticosa, the number of soil microorganisms, available phosphorus, iron, copper, zinc, manganese, exchangeable calcium and magnesium in soil. The physiological and biochemical characteristics of $A$. fruticosa seedling were analysed under different concentrations of A. niger, and the interaction effect between the A. niger and the A. fruticose was revealed, so as to provide theoretical and technical support for guiding the large-scale production and cultivation in the ecological restoration of rock side slope. 


\section{Materials and methods}

\section{The tested seeds of A. fruticosa}

Seeds of $A$. fruticosa were collected from Taihang mountain in Henan province. It was preserved in the Key Laboratory of Soil and Water Conservation and Ecological Restoration in Nanjing Forestry University.

\section{Collection of soil and rock samples}

Soil samples were taken from the closed mine in Jindingshan (E 120 $30^{\prime}$, N31 ${ }^{\circ} 17^{\prime}$ ) in Suzhou, Jiangsu. The content of soil organic matter $(\mathrm{OM})$ was $13.67 \mathrm{~g} \cdot \mathrm{kg}^{-1}$, total nitrogen (N) $0.92 \mathrm{~g} \cdot \mathrm{kg}^{-1}, \mathrm{pH} 7.10$, available $\mathrm{P}$ was $9.01 \mathrm{mg} \cdot \mathrm{kg}^{-1}$, exchangeable calcium was $9.70 \mathrm{cmol} \cdot \mathrm{kg}^{-1}$, exchangeable magnesium was $3.16 \mathrm{cmol} \cdot \mathrm{kg}^{-1}$, effectiveness of iron, manganese, copper, zinc was $2.66,5.24,0.50,1.23 \mathrm{mg} \cdot \mathrm{kg}^{-1}$ respectively in tested soil. Samples were sterilized at $121^{\circ} \mathrm{C}$ for $20 \mathrm{~min}$.

The rocks used in this study are porphyritic granites. The collected samples were placed in a sterile kraft bag and stored in a refrigerator at $-20{ }^{\circ} \mathrm{C}$. Fresh rock samples used in the experiment were washed with distilled water, dried naturally, ground, screened with 100 mesh, particle size $<90 \mu \mathrm{m}$, and sterilized under high pressure at $121^{\circ} \mathrm{C}$ for $20 \mathrm{~min}$.

\section{Testing strain}

A. niger strain XF-1 was activated, inoculated and fermented in PD culture solution for $72 \mathrm{~h}$ for later use.

\section{Medium and preparation}

PD medium (liquid): $200 \mathrm{~g}$ of diced potatoes were boiled for $20 \mathrm{~min}$, filtered by 8 layers of gauze to remove residue. $20 \mathrm{~g}$ of glucose was added in it, and distilled water was added to $1000 \mathrm{~mL}$. Then, the potatoes were thoroughly stirred and sterilized at $115^{\circ} \mathrm{C}$ for $20 \mathrm{~min}(\mathrm{Wu}, 2018)$.

\section{Seed treatment and seedling cultivation of A. fruticosa}

Seeds of $A$. fruticosa were soaked in sodium hypochlorite solution (2.5\% of active chlorine) for $10 \mathrm{~min}$ to eliminate the bacteria on the surface of the seed, washed several times with sterile water, put on the sterilized tray containing quartz sand (hand knead as dough, openhanded as powder), covered with a sterile gauze, then put in the darkness of the incubator at $28{ }^{\circ} \mathrm{C}$. Right amount water was sprayed to maintain appropriate humidity every day, sprouting seed germinated after $4 \mathrm{~d}$, the consistent germinated seeds were selected and transferred to the pot for culture.

The pots $(12.5 \mathrm{~cm}$ in diameter and $14.5 \mathrm{~cm}$ in height) used in the experiment were filled with $1.0 \mathrm{~kg}$ of soil and $100 \mathrm{~g}$ of granite powder each, and were divided into two groups: one group was planted with A. fruticosa, and the other group was not planted with $A$. fruticosa. Three plants were planted in each pot. When the plants emerged for 10 days, $A$. niger fermentation broth was diluted by 50, 100 and 200 times respectively. and poured into the two groups of the test bowls. A total of $5 \mathrm{~mL}$ irrigation was applied at one time, and tap water irrigation was applied for control treatment. The experimental treatments and their codes were shown in Table 1. The treatments of planting $A$. 
fruticosa were $\mathrm{CK}\left(\mathrm{T}_{0}-\mathrm{A}\right), \mathrm{T}_{50}-\mathrm{A}, \mathrm{T}_{100}-\mathrm{A}, \mathrm{T}_{200}-\mathrm{A}$. The treatments without $A$. fruticosa were CK $\left(\mathrm{T}_{0}\right), \mathrm{T}_{50}, \mathrm{~T}_{100}$ and $\mathrm{T}_{200}$, as shown in Table 1. Each treatment was repeated 10 times. The experiment began on May 20, 2017, with a growth cycle of three months, and $50 \mathrm{~mL}$ water was sprayed on every other day to maintain appropriate humidity.

Table 1. The different treatments and corresponding codes

\begin{tabular}{c|c|c}
\hline Treatment & Without A. fruticosa group & Planting A. fruticosa group \\
\hline CK & CK $\left(\mathrm{T}_{0}\right)$ & CK $\left(\mathrm{T}_{0}-\mathrm{A}\right)$ \\
50 times nutrient solution of A. niger XF-1 & $\mathrm{T}_{50}$ & $\mathrm{~T}_{50}-\mathrm{A}$ \\
100 times nutrient solution of A. niger XF-1 & $\mathrm{T}_{100}$ & $\mathrm{~T}_{100}-\mathrm{A}$ \\
200 times nutrient solution of A. niger XF-1 & $\mathrm{T}_{200}$ & $\mathrm{~T}_{200}-\mathrm{A}$ \\
\hline
\end{tabular}

\section{Determination of microbial quantity in rhizosphere}

A. fruticosa was removed from soil, $0.2 \mathrm{~g}$ plant roots were carefully cut and placed in $100 \mathrm{~mL}$ sterile water, diluted and spread on PDA solid medium, cultured at $28{ }^{\circ} \mathrm{C}$ for 72 $\mathrm{h}$ and counted. A. niger PDA plates were cultivated, $1 \mathrm{~g}$ of the soil of various treatments were taken and put in a $100 \mathrm{~mL}$ conical flask, $50 \mathrm{~mL}$ sterile water was added in it, it was diluted it into four gradient, namely $10^{-1}, 10^{-2}, 10^{-3}$, and $10^{-4}$ in super clean workbench after $3 \mathrm{~h}$, and then last two gradient coating to its corresponding medium were selected and put through the shaking table at $28^{\circ} \mathrm{C}$. After $4 \mathrm{~d}$, the number of tested fungi in the soil was observed and recorded.

\section{Determination of soil pH value, effective $\mathrm{P}, \mathrm{Cu}, \mathrm{Zn}, \mathrm{Fe}, \mathrm{Mn}$, exchangeable $\mathrm{Ca}$, and $\mathrm{Mg}$}

PH value of soil was determined by PHS-3CT. The available phosphorus in soil was determined by sodium bicarbonate extraction-molybdenum antimony anticolorimetric method (Olsen method). The contents of exchangeable $\mathrm{Ca}$ and $\mathrm{Mg}$ in soil were determined by $1 \mathrm{~mol} \cdot \mathrm{L}^{-1}$ ammonium acetate exchangeable atomic absorption spectrometry (Bao, 1981). The soil availability of $\mathrm{Cu}, \mathrm{Zn}, \mathrm{Fe}$ and $\mathrm{Mn}$ were determined by DTPA solution extraction-atomic absorption spectrometry (Zhang, 2004).

\section{Determination of chlorophyll content}

Chlorophyll content of $A$. fruticosa was extracted by ethanol and $80 \%$ acetone mixture $\left(V\right.$ ethanol: $V_{80 \%}$ acetone $)=1: 1$ ), and determined by colorimetry at wavelengths of $646 \mathrm{~nm}$ and $663 \mathrm{~nm}$, respectively, to calculate chlorophyll content of $w($ Chla $), w($ Chlb) and $w$ (Chl) (Wang et al., 2017).

\section{Determination of plant height and biomass of A. fruticosa}

Put the whole pot of A. fruticosa under the tap pipe, rinse the soil with slender water. Take out the whole plant, clean it with deionized water several times, and then dry the water on the root surface with absorbent paper. The A. fruticosa roots were cut off, the height, root length and fresh weight were measured respectively. The whole plant of $A$. fruticosa were washed with deionized water, and then water was removed at $105^{\circ} \mathrm{C}$, and dried at $85^{\circ} \mathrm{C}$ to a constant mass. The dry and fresh mass of each part of $A$. fruticosa were recorded, and the root-crown ratio was calculated. 


\section{Scanning electron microscope observation of root complex of A. fruticosa}

The root part of $A$. fruticosa was cut off with scissors, put in a $1.5 \mathrm{~mL}$ centrifuge tube, and placed in an oven at $40{ }^{\circ} \mathrm{C}$. After drying, the samples were fixed on the copper table of scanning electron microscope, and sprayed metal. The root of the plant was analyzed by Hitanchi-S3400N scanning electron microscope and energy spectrometer.

\section{Statistical analysis method of data}

Excel 2010 was used to process the data, and SPSS 20.0 was used for variance analysis.

\section{Results}

Influence of A. niger strain XF-1 on the number of microorganisms tested in soil rhizosphere

The determination results from Figure 1 showed that all the quantity of rhizosphere microorganisms of A. fruticosa inoculated with A. niger were above $10^{3} \mathrm{cfu}^{-\mathrm{g}^{-1}}$, which was significantly higher than that of control. With the decrease of irrigation concentration, the number of rhizosphere microorganisms decreased gradually. The number of microorganisms of $A$. niger XF-1 treated with $\mathrm{T}_{50}-\mathrm{A}$ was maximum, reached $3.16 \times 10^{4}$, which was significantly higher than other treatments. It indicated that A. niger XF-1 could colonize the rhizosphere of A. fruticosa, and then interacted with plants to form a soil-microbe-plant system with soil.

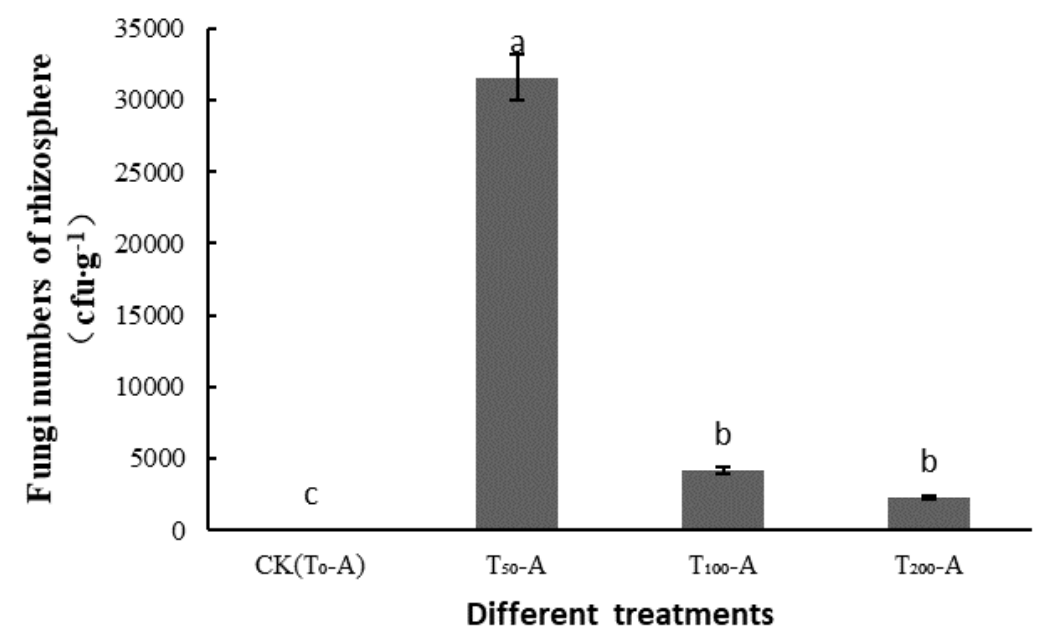

Figure 1. Fungi numbers in A. fruticosa rhizosphere in different treatments

\section{Effects of A. niger XF-1 on soil pH value}

As shown in Table 2, the $\mathrm{pH}$ values of the treated group after irrigation of $A$. niger XF-1 fermentation broth were significantly lower than that of the control group and were slightly acidic, indicating that irrigation of A. niger XF-1 nutrient solution had a significant impact on the soil $\mathrm{pH}$ value. The $\mathrm{pH}$ value of soil of planting A. fruticosa treated with the same $A$. niger concentration was lower than that without planting $A$. fruticosa, but the difference was not significant, indicating that the growth of $A$. niger 
strain XF-1 secreted organic acids to reduce the soil $\mathrm{pH}$ value. Compared with the control without A. fruticosa, the soil $\mathrm{pH}$ values of treatments of the control group of planting A. fruticosa, diluted 50 times, diluted 100 times and diluted 200 times decreased to 7.0, 6.2, 6.1 and 6.3 respectively, and the $\mathrm{pH}$ value of the treatment diluted 100 times decreased to the lowest, indicating that the organic acid produced by watering at this concentration was the most.

Table 2. $p H$ values of different dilutions of fermentation broth of A. niger strain XF-1

\begin{tabular}{c|c}
\hline Treatment & pH value \\
\hline CK $\left(\mathrm{T}_{0}-\mathrm{A}\right)$ & $7.0 \pm 0.09 \mathrm{a}$ \\
$\mathrm{CK}\left(\mathrm{T}_{0}\right)$ & $7.1 \pm 0.12 \mathrm{a}$ \\
$\mathrm{T}_{50}-\mathrm{A}$ & $6.2 \pm 0.11 \mathrm{~b}$ \\
$\mathrm{~T}_{50}$ & $6.3 \pm 0.08 \mathrm{~b}$ \\
$\mathrm{~T}_{100}-\mathrm{A}$ & $6.1 \pm 0.19 \mathrm{~b}$ \\
$\mathrm{~T}_{100}$ & $6.2 \pm 0.07 \mathrm{~b}$ \\
$\mathrm{~T}_{200}-\mathrm{A}$ & $6.3 \pm 0.13 \mathrm{~b}$ \\
$\mathrm{~T}_{200}$ & $6.4 \pm 0.08 \mathrm{~b}$ \\
\hline
\end{tabular}

Different letters after the same column of numbers indicate significant differences at the 0.05 level

\section{Influence of A. niger strain XF-1 on effective $P, C u, Z n, F e$ and $M n$ in soil}

As can be seen from Table 3, after watering A. niger strain XF-1 nutrient solution, the content of effective $\mathrm{P}$ in soil was generally higher than that of $\mathrm{CK}\left(\mathrm{T}_{0}-\mathrm{A}\right.$ and $\mathrm{T}_{0}$ ). For dilution of 50 times, 100 times and 200 times, the available $\mathrm{P}$ content of soil planted with $A$. fruticosa increased by $16.9 \%, 35.91 \%$ and $26.76 \%$, respectively compared with CK $\left(\mathrm{T}_{0}-\mathrm{A}\right)$, and that of soil without A. fruticosa increased by $17.69 \%, 32.24 \%$ and $23.32 \%$, respectively compared with $\mathrm{CK}\left(\mathrm{T}_{0}\right)$. After watering A. niger strain XF-1 nutrient solution, the contents of effective $\mathrm{Fe}, \mathrm{Cu}$, zinc, and $\mathrm{Mn}$ in the soil were higher than $\mathrm{CK}\left(\mathrm{T}_{0}-\mathrm{A}\right.$ and $\left.\mathrm{T}_{0}\right)$. The content of effective Fe of treatments of planting $A$. fruticosa diluted 50 times, 100 times and 200 times in the soil after 90 days increased by $24.04 \%, 27.10 \%$ and $25.95 \%$ than $\mathrm{CK}\left(\mathrm{T}_{0-\mathrm{A}}\right)$, respectively, the content of effective $\mathrm{Cu}$ in soil increased by $4.91 \%, 11.48 \%$ and $6.56 \%$ than $\mathrm{CK}\left(\mathrm{T}_{0}-\mathrm{A}\right)$, respectively, the content of effective zinc in soil increased by $6.30 \%, 7.87 \%$ and $7.09 \%$ than $\mathrm{CK}\left(\mathrm{T}_{0}-\mathrm{A}\right)$ ,respectively, the content of available $\mathrm{Mn}$ in soil increased by $6.65 \%, 11.49 \%$ and $6.85 \%$ than $\mathrm{CK}\left(\mathrm{T}_{0}-\mathrm{A}\right)$, respectively. For dilution of 50 times, 100 times and 200 times, the content of effective $\mathrm{Fe}$ of treatments without A. fruticosa in soil after 90 days increased by $26.89 \%, 26.89 \%$ and $25.76 \%$ than $\mathrm{CK}\left(\mathrm{T}_{0}\right)$, respectively, and the content of effective $\mathrm{Cu}$ in soil increased by $1.61 \%, 11.29 \%$ and $6.45 \%$ than $\mathrm{CK}\left(\mathrm{T}_{0}\right)$, respectively, the content of available $\mathrm{Zn}$ in soil increased by $5.43 \%, 6.30 \%$ and $4.65 \%$ than CK $\left(\mathrm{T}_{0}\right)$, respectively, and the content of available Mn in soil increased by $6.85 \%$, $11.49 \%$ and $6.85 \%$ than $\mathrm{CK}\left(\mathrm{T}_{0}\right)$, respectively, but the difference was not significant.

\section{Effects of A. niger strain XF-1 on exchangeable Ca and Mg in soil}

As can be seen from Table 4, after watering of A. niger XF-1 nutrient solution, the contents of exchangeable $\mathrm{Ca}$ and $\mathrm{Mg}$ in soil were higher than $\mathrm{CK}\left(\mathrm{T}_{0}\right)$ and $\mathrm{CK}\left(\mathrm{T}_{0}-\mathrm{A}\right)$, but the difference were not significant. 90 days after watering, the contents of 
exchangeable $\mathrm{Ca}$ of treatments diluted 50 times, 100 times and 200 times with planting A. fruticosa in soil were $1.23 \%, 1.91 \%$ and $0.90 \%$ higher than CK $\left(\mathrm{T}_{0}-\mathrm{A}\right)$, and the contents of exchangeable $\mathrm{Mg}$ of that in soil were $0.61 \%, 1.22 \%$ and $0.91 \%$ higher than $\mathrm{CK}\left(\mathrm{T}_{0}-\mathrm{A}\right)$, respectively. The contents of exchangeable $\mathrm{Ca}$ of treatments diluted 50 times, 100 times and 200 times without planting A. fruticosa in soil after 90 days increased by $1.57 \%, 2.68 \%$ and $1.12 \%$ than $\mathrm{CK}\left(\mathrm{T}_{0}\right)$ respectively, and the content of exchangeable $\mathrm{Mg}$ of that in soil increased by $0.61 \%, 1.21 \%$ and $0.91 \%$ than $\mathrm{CK}\left(\mathrm{T}_{0}\right)$, respectively, but there was no significant difference.

Table 3. Effect of different dilution fermentation broth of A. niger $X F-1$ on available $P, K$, $\mathrm{Cu}, \mathrm{Zn}, \mathrm{Fe}, \mathrm{Mn}\left(\mathrm{mg} \mathrm{kg}^{-1}\right)$ in soil

\begin{tabular}{c|c|c|c|c|c}
\hline Treatment & $\mathbf{P}$ & $\mathbf{C u}$ & $\mathbf{Z n}$ & $\mathbf{F e}$ & $\mathbf{M n}$ \\
\hline $\mathrm{CK}\left(\mathrm{T}_{0}-\mathrm{A}\right)$ & $7.10 \pm 0.12 \mathrm{~b}$ & $0.53 \pm 0.01 \mathrm{~b}$ & $1.27 \pm 0.03 \mathrm{~b}$ & $2.62 \pm 0.05 \mathrm{~b}$ & $4.96 \pm 0.02 \mathrm{~b}$ \\
$\mathrm{CK}\left(\mathrm{T}_{0}\right)$ & $7.63 \pm 0.19 \mathrm{~b}$ & $0.62 \pm 0.02 \mathrm{a}$ & $1.29 \pm 0.04 \mathrm{~b}$ & $2.64 \pm 0.06 \mathrm{~b}$ & $4.96 \pm 0.06 \mathrm{~b}$ \\
$\mathrm{~T}_{50} \mathrm{~A}$ & $8.30 \pm 0.09 \mathrm{~b}$ & $0.64 \pm 0.02 \mathrm{a}$ & $1.35 \pm 0.02 \mathrm{a}$ & $3.25 \pm 0.04 \mathrm{a}$ & $5.29 \pm 0.04 \mathrm{ab}$ \\
$\mathrm{T}_{50}$ & $8.98 \pm 0.13 \mathrm{ab}$ & $0.63 \pm 0.01 \mathrm{a}$ & $1.36 \pm 0.01 \mathrm{a}$ & $3.29 \pm 0.03 \mathrm{a}$ & $5.30 \pm 0.03 \mathrm{a}$ \\
$\mathrm{T}_{100} \mathrm{~A}$ & $9.65 \pm 0.08 \mathrm{a}$ & $0.68 \pm 0.01 \mathrm{a}$ & $1.37 \pm 0.03 \mathrm{a}$ & $3.33 \pm 0.02 \mathrm{a}$ & $5.53 \pm 0.05 \mathrm{a}$ \\
$\mathrm{T}_{100}$ & $10.09 \pm 0.15 \mathrm{a}$ & $0.69 \pm 0.02 \mathrm{a}$ & $1.37 \pm 0.02 \mathrm{a}$ & $3.35 \pm 0.01 \mathrm{a}$ & $5.53 \pm 0.03 \mathrm{a}$ \\
$\mathrm{T}_{200} \mathrm{~A}$ & $9.00 \pm 0.08 \mathrm{a}$ & $0.65 \pm 0.01 \mathrm{a}$ & $1.36 \pm 0.01 \mathrm{a}$ & $3.30 \pm 0.03 \mathrm{a}$ & $5.30 \pm 0.06 \mathrm{a}$ \\
$\mathrm{T}_{200}$ & $9.41 \pm 0.12 \mathrm{a}$ & $0.66 \pm 0.01 \mathrm{a}$ & $1.35 \pm 0.02 \mathrm{a}$ & $3.32 \pm 0.02 \mathrm{a}$ & $5.30 \pm 0.07 \mathrm{a}$ \\
\hline
\end{tabular}

Different letters after the same column of numbers indicate significant differences at the 0.05 level

Table 4. Effect of different dilution fermentation broth of A. niger on exchangeable Ca and $\mathrm{Mg}\left(\mathrm{mg} \cdot \mathrm{kg}^{-1}\right)$ in soil

\begin{tabular}{c|c|c}
\hline Treatment & Ca & Mg \\
\hline $\mathrm{CK}\left(\mathrm{T}_{0}-\mathrm{A}\right)$ & $8.92 \pm 0.04 \mathrm{a}$ & $3.29 \pm 0.07 \mathrm{a}$ \\
$\mathrm{CK}\left(\mathrm{T}_{0}\right)$ & $8.94 \pm 0.05 \mathrm{a}$ & $3.30 \pm 0.09 \mathrm{a}$ \\
$\mathrm{T}_{50}-\mathrm{A}$ & $9.03 \pm 0.06 \mathrm{a}$ & $3.31 \pm 0.05 \mathrm{a}$ \\
$\mathrm{T}_{50}$ & $9.08 \pm 0.13 \mathrm{a}$ & $3.32 \pm 0.07 \mathrm{a}$ \\
$\mathrm{T}_{100}-\mathrm{A}$ & $9.09 \pm 0.08 \mathrm{a}$ & $3.33 \pm 0.08 \mathrm{a}$ \\
$\mathrm{T}_{100}$ & $9.18 \pm 0.15 \mathrm{a}$ & $3.34 \pm 0.07 \mathrm{a}$ \\
$\mathrm{T}_{200}-\mathrm{A}$ & $9.00 \pm 0.11 \mathrm{a}$ & $3.32 \pm 0.05 \mathrm{a}$ \\
$\mathrm{T}_{200}$ & $9.04 \pm 0.12 \mathrm{a}$ & $3.33 \pm 0.06 \mathrm{a}$ \\
\hline
\end{tabular}

Same letters after the same column of numbers indicate no significant differences at the 0.05 level

\section{Effect of A. niger strain XF-1 on chlorophyll content of A. fruticosa}

As can be seen from Figure 2, the photosynthetic pigment content of A. fruticosa seedlings could be increased to different degrees after watering dilution nutrient solution of $A$. niger at different multiples. The contents of chlorophyll a, chlorophyll $\mathrm{b}$ and total chlorophyll in treatments of watering diluted 100 times were the highest, higher than that in treatments of watering diluted 50 times, but the difference was not significant $(p<0.05)$. The content of chlorophyll a and total chlorophyll were significantly higher than that of watering diluted 200 times, and significantly higher than that of control $(p<0.05)$. There was no significant difference in chlorophyll $\mathrm{b}$ content. The contents of 
chlorophyll a, chlorophyll $\mathrm{b}$ and total chlorophyll in treatments of watering diluted 50 times were higher than that in treatments of watering diluted 200 times, but the difference were not significant $(p<0.05)$. The contents of chlorophyll a and total chlorophyll were significantly higher than that of the control group $\left(\mathrm{T}_{0}\right.$ and $\left.\mathrm{T}_{0-\mathrm{A}}\right)$, while the content of chlorophyll $\mathrm{b}$ was not significantly different $(p<0.05)$. The contents of chlorophyll a, chlorophyll $b$ and total chlorophyll in the watered locust with a concentration of 200 times dilution were higher than that of the control $\left(\mathrm{T}_{0-\mathrm{A}}\right)$, the contents of chlorophyll a and total chlorophyll were significantly higher than that of the control $\left(\mathrm{T}_{0-\mathrm{A}}\right)$, and the content difference of chlorophyll $\mathrm{b}$ was not significant $(p<0.05)$. To sum up, the results showed that the contents of chlorophyll a, b and total chlorophyll of $A$. fruticosa in treatments of watering diluted 100 times were higher than that in treatments of watering diluted 50 times, and the contents of chlorophyll a, b and total chlorophyll of A. fruticosa in treatments of watering diluted 200 times were the lowest. The chlorophyll content was $\mathrm{T}_{100}-\mathrm{A}>\mathrm{T}_{50}-\mathrm{A}>\mathrm{T}_{200}-\mathrm{A}$ in turn.

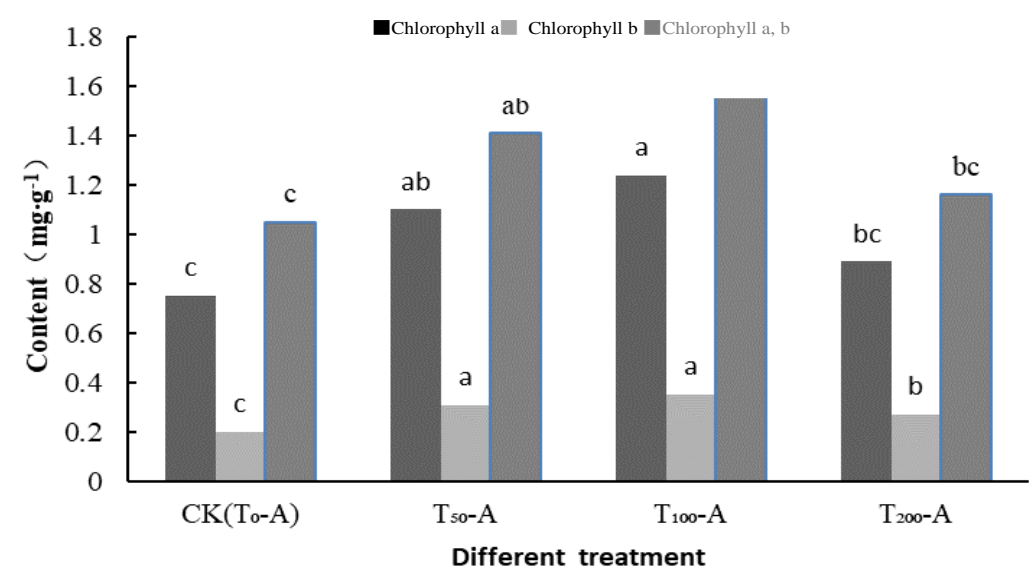

Figure 2. Effect of different dilution fermentation broth of A. niger XF-1 on chlorophyll content of Amorpha fruticosa

\section{Effect of A. niger XF-1 on plant height and biomass of A. fruticosa}

Effect of watering three kinds of different dilution concentrations of A. niger fermentation broth on plant height, root system and biomass were shown in Figures 3 and 4 and Tables 5 and 6.

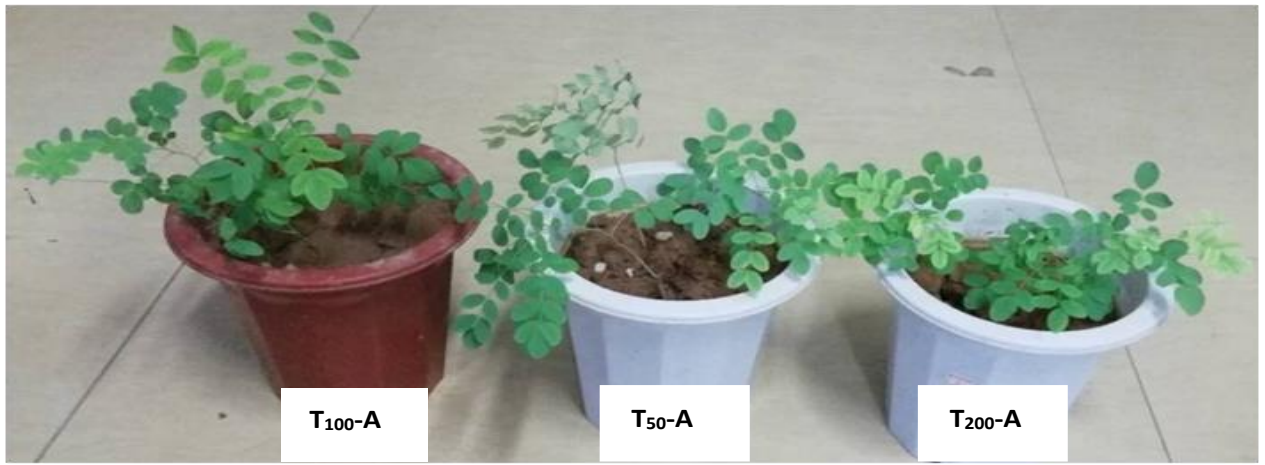

Figure 3. Effect of different dilution fermentation broth of A. niger XF-1 on the growth of A. fruticosa 


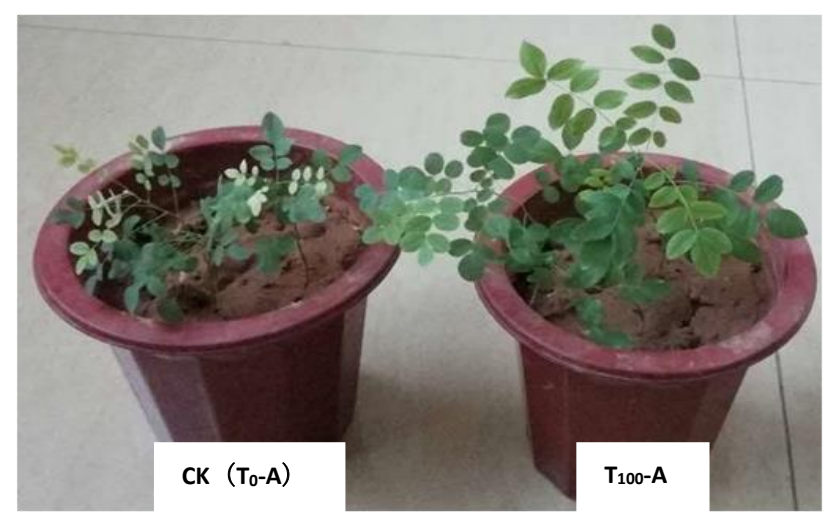

Figure 4. Comparison of plant height of $A$. fruticosa between treatment $T_{100}-A$ and $C K\left(T_{0}-A\right)$

Tables 5 and 6 show that treatments of watering different dilution concentrations of fermentation broth of $A$. niger XF-1 can obviously promote the growth of A. fruticosa above ground. The analysis of plant height, fresh and dry weight above ground of $A$. fruticosa showed that the promoting effect of $\mathrm{T}_{100}-\mathrm{A}$ was the best, of $\mathrm{T}_{200}-\mathrm{A}$ was the second, of $\mathrm{T}_{50}-\mathrm{A}$ was the worst. The plant height of $A$. fruticosa for $\mathrm{T}_{100}-\mathrm{A}$ was $6.09 \mathrm{~cm}$, $2.02 \mathrm{~cm}$ and $4.20 \mathrm{~cm}$, which was significantly higher than that for $\mathrm{T}_{0}-\mathrm{A}, \mathrm{T}_{50}-\mathrm{A}$ and $\mathrm{T}_{200}-\mathrm{A}$ respectively. The fresh weight above ground for $\mathrm{T}_{100}-\mathrm{A}$ was $0.11 \mathrm{~g}, 0.21 \mathrm{~g}$ and $0.24 \mathrm{~g}$, which was significantly lower than that for $\mathrm{T}_{50}-\mathrm{A}, \mathrm{T}_{200}-\mathrm{A}$ and $\mathrm{T}_{0}-\mathrm{A}$, respectively. The dry weight above ground for $\mathrm{T}_{100}-\mathrm{A}$ was $0.04 \mathrm{~g}, 0.08 \mathrm{~g}$ and $0.12 \mathrm{~g}$, which was significantly lower than that for $\mathrm{T}_{50}-\mathrm{A}, \mathrm{T}_{200}-\mathrm{A}$ and $\mathrm{T}_{0}-\mathrm{A}$, respectively. The promoting ability of the three kinds of $A$. niger XF-1 nutrient solution to root length of A. fruticosa was $\mathrm{T}_{100-}$ $\mathrm{A}>\mathrm{T}_{50}-\mathrm{A}>\mathrm{T}_{200}-\mathrm{A}$, and the root length of $A$. fruticosa for $\mathrm{T}_{100}-\mathrm{A}$ was $2.34 \mathrm{~cm}, 3.92 \mathrm{~cm}$, and $3.15 \mathrm{~cm}$, which was significantly higher than that for $\mathrm{T}_{50}-\mathrm{A}, \mathrm{T}_{200}-\mathrm{Aand} \mathrm{T}_{0}-\mathrm{A}$, respectively. The root diameter circumference and dry weight of A. fruticosa for the three kinds of $A$. niger XF-1 nutrient solution were significantly lower than that for $\mathrm{T}_{0}-\mathrm{A}$. The root diameter circumference of $A$. fruticosa for $\mathrm{T}_{100-\mathrm{A}}$ was $0.26 \mathrm{~mm}$ and $0.58 \mathrm{~mm}$, which was significantly higher than that for $\mathrm{T}_{50}-\mathrm{A}$ and $\mathrm{T}_{200}-\mathrm{A}$ respectively, but $0.21 \mathrm{~mm}$ was significantly lower than that for $\mathrm{T}_{0}-\mathrm{A}$. Root fresh weight of $A$. fruticosa for $\mathrm{T}_{100}-\mathrm{A}$ was significantly higher $(0.04 \mathrm{~g}$ and $0.05 \mathrm{~g})$ than that for $\mathrm{T}_{50}-\mathrm{A}$ and $\mathrm{T}_{200}-\mathrm{A}$ respectively, but $0.04 \mathrm{~g}$ was significantly lower than that for $\mathrm{T}_{0}-\mathrm{A}$. The dry weight of root system of $A$. fruticosa for $\mathrm{T}_{100}-\mathrm{A}$ was significantly lower than that for $\mathrm{T}_{50} \mathrm{~A}$ and $\mathrm{T}_{0}-\mathrm{A}$ by $0.02 \mathrm{~cm}$ and $0.04 \mathrm{~cm}$ respectively, and significantly higher than that for $\mathrm{T}_{200}-\mathrm{A}$ by $0.02 \mathrm{~cm}$. Compared with the control $\mathrm{T}_{0}-\mathrm{A}$, the root cap ratio of $A$. fruticosa with different concentrations of $A$. niger XF-1 fermentation broth was significantly decreased, indicating that $A$. niger XF-1 nutrient solution improved the condition of nutrition supplies of A. fruticosa, was advantageous to the rapid growth of above round parts. Among them, $\mathrm{T}_{100}$-A treatment promoted the growth of $A$. fruticosa the fastest, but there was no significant difference with the other two concentrations of $A$. niger XF-1 nutrient solution. On the whole, $\mathrm{T}_{100^{-}}$ A treatment has the best effect in promoting the growth of A. fruticosa, which is suggested as a reference for ecological restoration.

\section{Scanning electron microscope (SEM) observation of root complex of A. fruticosa}

The above studies indicated that A. niger XF-1 had a significant effect on promoting A. fruticosa. In order to better study the weathering of plants and microorganisms on 
granite rocks, the effect of A. niger XF-1 on the granite and the roots of A. fruticosa was observed by SEM. As can be seen from Figure 5, the surface of the granite which is not planted with A. fruticosa and not inoculated with A. niger XF-1 was relatively smooth, angular and without a large number of fragments. However, A. niger XF-1 was distributed on the surface of the granite treated by inoculation without A. fruticosa, and there were a large number of granular substances, even the presence of fungal secretions. It can be seen that the granite underwent different degrees of weathering under the action of $A$. niger XF-1.

Table 5. Effect of different dilution fermentation broth of A. niger XF-1 on plant height, root length and diameter circumference of A. fruticosa

\begin{tabular}{c|c|c|c}
\hline Treatment & Plant height $(\mathbf{c m})$ & Root length $(\mathbf{c m})$ & Diameter circumference $(\mathbf{m m})$ \\
\hline $\mathrm{CK}\left(\mathrm{T}_{0}-\mathrm{A}\right)$ & $7.43 \pm 0.19 \mathrm{~d}$ & $9.42 \pm 0.22 \mathrm{c}$ & $2.03 \pm 0.45 \mathrm{a}$ \\
$\mathrm{T}_{50}-\mathrm{A}$ & $11.50 \pm 0.17 \mathrm{~b}$ & $10.23 \pm 0.26 \mathrm{~b}$ & $1.56 \pm 0.09 \mathrm{c}$ \\
$\mathrm{T}_{100}-\mathrm{A}$ & $13.52 \pm 0.35 \mathrm{a}$ & $12.57 \pm 0.69 \mathrm{a}$ & $1.82 \pm 0.06 \mathrm{~b}$ \\
$\mathrm{~T}_{200}-\mathrm{A}$ & $9.32 \pm 0.23 \mathrm{c}$ & $8.65 \pm 0.19 \mathrm{~d}$ & $1.24 \pm 0.03 \mathrm{~d}$ \\
\hline
\end{tabular}

Different letters after the same column of numbers indicate significant differences at the 0.05 level

Table 6 Effect of different dilution fermentation of A. niger XF-1 on the above ground part and root biomass of A. fruticosa

\begin{tabular}{|c|c|c|c|c|c|c|c|}
\hline \multirow{2}{*}{ Treatment } & \multicolumn{3}{|c|}{ Fresh weight (g•plant ${ }^{-1}$ ) } & \multicolumn{3}{|c|}{ Dry weight $\left(g \cdot\right.$ plant $\left.^{-1}\right)$} & \multirow{2}{*}{$\begin{array}{c}\text { Root cap } \\
\text { ratio }\end{array}$} \\
\hline & Overground & Root system & Total & Overground & Root system & & \\
\hline & $0.40 \pm 0.09 \mathrm{~d}$ & & & & & $0.51 \pm 0.09 \mathrm{c}$ & $0.96 \mathrm{a}$ \\
\hline & $0.55 \pm 0.09 \mathrm{~b}$ & $0.37 \pm 0.09 \mathrm{c}$ & & $0.34 \pm 0.09 \mathrm{a}$ & $0.21 \pm 0.09 \mathrm{c}$ & $0.55 \pm 0.09 \mathrm{~b}$ & \\
\hline & $0.66 \pm 0.09 \mathrm{a}$ & $0.41 \pm 0.09 b$ & & $0.38 \pm 0.09 \mathrm{a}$ & & $0.61 \pm 0.09 \mathrm{a}$ & \\
\hline $\mathrm{T}_{200}-\mathrm{A}$ & $0.45 \pm 0.09 \mathrm{c}$ & $0.36 \pm 0.09 \mathrm{c}$ & $0.80 \mathrm{c}$ & $0.30 \pm 0.09 \mathrm{ab}$ & $0.19 \pm 0.09 \mathrm{~d}$ & $0.49 \pm 0.09 \mathrm{~d}$ & $0.63 b$ \\
\hline
\end{tabular}

Different letters after the same column of numbers indicate significant differences at the 0.05 level

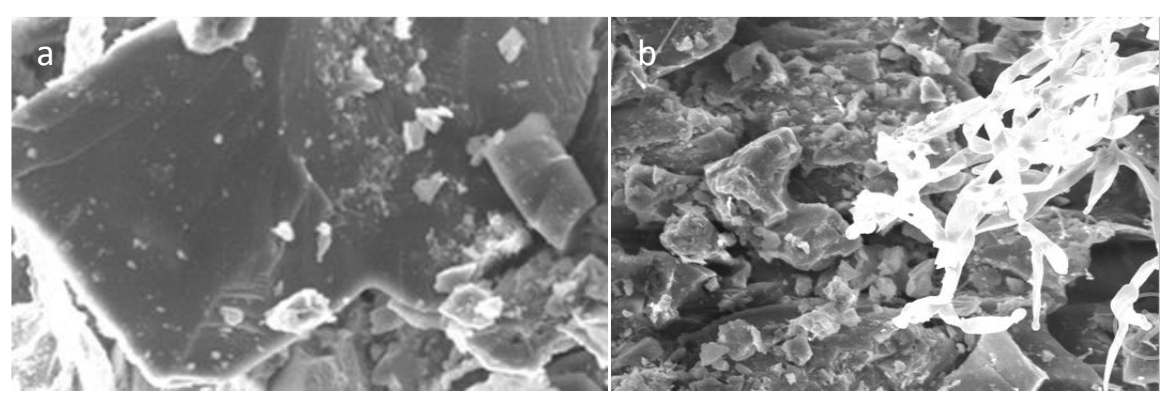

Figure 5. SEM photos of granite surfaces without planting A. fruticosa. (a) Granite surface without A. niger strain XF-1. (b) Granite surface with A. niger XF-1

Figure 6 showed the scanning electron microscope (SEM) images of the root system of plant and the attached granitoid particle complexes planted with A. fruticosa without inoculation. As can be seen from the picture, the root (or root hair) of the A. fruticosa can absorb fragments of granite. According to the result of energy spectrum analysis, the weathering effect of granites adsorbed on the root surface of $A$. fruticosa is not obvious. 


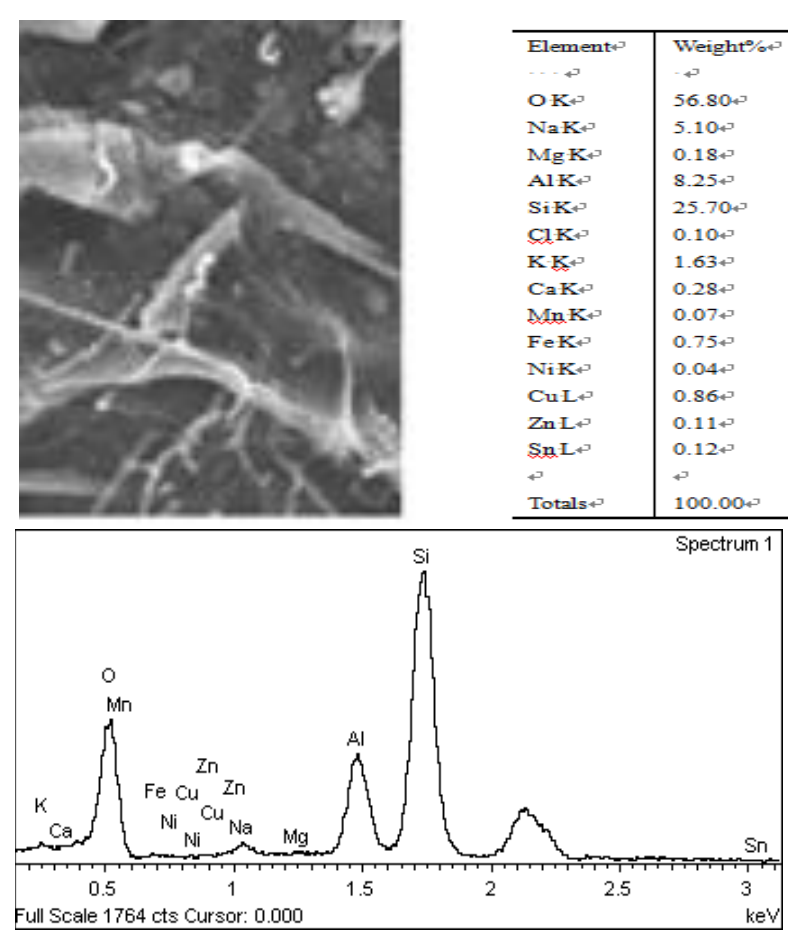

Figure 6. SEM photos of granite planted A. fruticosa without A. niger XF-1

Figure 7 is a scanning electron microscope image of the root system and the attached granitoid particle complex of $A$. fruticosa by inoculation. It can be seen from the figure that there were a large secretions of $A$. niger XF-1 and granites on the root system surface of $A$. fruticosa treated by inoculation. It can be seen that $A$. niger XF- 1 could colonize the surface of granite rocks and root of A. fruticosa, and multiply to produce hyphae and secrete metabolites. According to the results of energy spectrum analysis, the surface of A. niger XF-1 and root system of A. fruticosa adsorbed a lot of elements. A. niger XF-1 had a significant effect on the granite weathering of the root surface of $A$. fruticosa.

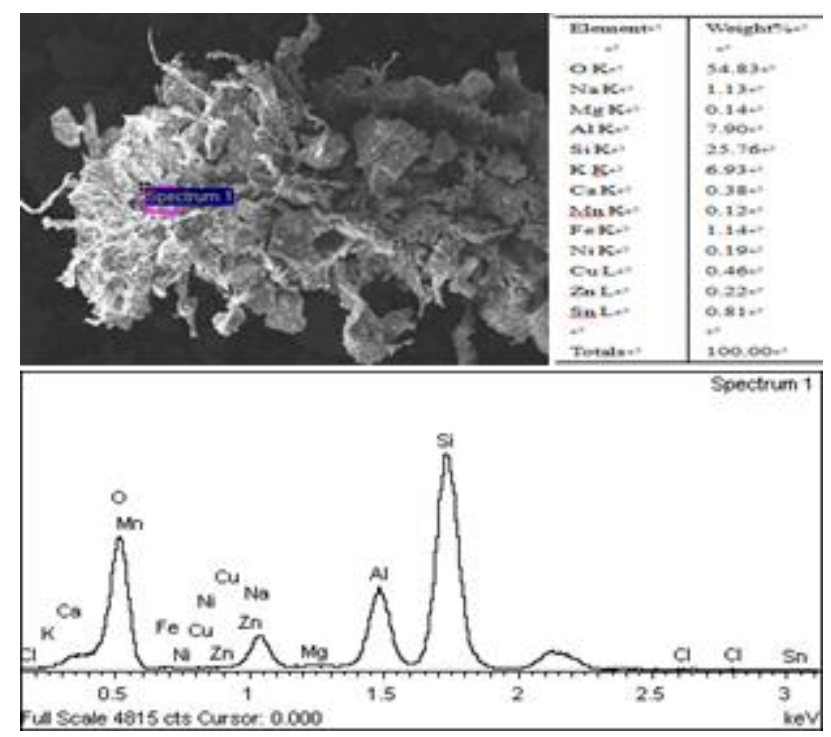

Figure 7. SEM photos of granite, that plant A. fruticosa, treated with A. niger XF-1 


\section{Discussion}

A. niger XF-1 can well colonize surfaces of plant roots and rock, appropriately reduce the soil $\mathrm{pH}$ value, increase the content of available phosphorus, iron, copper, zinc and manganese in the soil, and promote the growth of plants and the increase of biomass. It is a strain that can effectively dissolve soil elements and promote the growth of plants. The results of this experiment showed that the $\mathrm{pH}$ value of soil was decreased from 7.1 to 6.1 after watering the fermentation broth of $A$. niger star in XF-1. The decrease of $\mathrm{pH}$ value was due to the strain producing a large amount of oxalic acid, lactic acid and succinic acid ( $\mathrm{Wu}, 2018)$. The secretion of organic acids is the main mechanism of releasing nutrient elements from rock minerals (Wu et al., 2017a, b). During the reproduction process in soil, microorganisms secrete organic acids, cause the increase of the number of $\mathrm{H}^{+}$in soil reduce the $\mathrm{pH}$ value in soil and can chelate with some plasmas such as iron, aluminum, calcium and so on, which makes the undissolved phosphorus render into effective phosphorus (Zhong et al., 2015), and the calcium, magnesium, iron, copper, zinc, silicon and other nutrients in soil can be activated with the increase of $\mathrm{H}^{+}$to improve the availability of these nutrients in the soil $(\mathrm{Wu}, 2018$; $\mathrm{Wu}, 2019)$. Meanwhile, microorganisms can also secrete polysaccharides, amino acids and other substances to directly improve plant stress resistance (Huang et al., 2009; Li et al., 2012).

In the process of screening microbial strains of weathered rock minerals from soil, in addition to its ability to weathering rock minerals, its role in plant-microbial systems should be considered. As the rhizosphere microorganism, the function of microbial strains may be influenced by other factors (Benoit et al., 2015). As living organisms, microbial strains also secrete metabolites, which may affect plant growth and development. For example, metabolites affect the effective absorption, and deposition of nutrients, the activity of plant pathogens, the occurrence and degree of plant diseases, and the stress resistance of plants, so as to promote or inhibit the growth of plants (Jiang et al., 2000). Saxena et al. have shown that applying bioinoculated A. niger K7 and biochar simultaneously is a good measure to improve soil fertility and crop yield. In the soil-plant experiment, all treatments significantly increased the growth, root nodule and yield of soybean plants $(p<0.05)$ (Saxena, 2016). Rhizosphere microorganisms stimulate plant growth because they produce a variety of plant growth hormones and vitamins in solution and in plants. These compounds can promote plant growth to some extent.

Nitrogen, phosphorus and potassium are essential elements for plant growth and development. Released nutrients by weathering rock mineral and substances secreted by metabolism for single strain cannot completely meet the requirements of plant growth. Therefore, using the mutual composite of microorganisms with different functions in soil, such as compound utilization of phosphorus-soluble microorganisms and microbial strains which can resolve nitrogen or potassium, can meet the plant's nutritional requirements. At present, the compounding and use of compound bacterial preparation has become a hot research problem, and if microbial strains are used in combination with microorganisms that can decompose the remaining chemical fertilizers and pesticides in the soil, or kill pests, or sterilize bacterials, and or improve physical and chemical properties of soil, it is bound to strengthen the ability of microorganisms to adapt to the environment, optimize the structure of soil, stimulate the accumulation of the microbial metabolites, and meet the supply of plant growth nutrients, which will benefit the rapid coverage of bare rock slope vegetation and promote the sustainable development of ecological restoration. 


\section{Conclusion}

In this study, the number of rhizosphere microorganisms was significantly higher than that of control group after inoculation. Moreover, with the increase of irrigation concentration, the number of rhizosphere microorganisms of A. fruticosa increased gradually. It indicated that $A$. niger XF-1 can colonize the rhizosphere of A. fruticosa, which is conductive to the formation of soil-microbial-plant system.

After inoculation with $A$. niger XF-1 fermentation broth, the $\mathrm{pH}$ value of soil decreased significantly. The contents of exchangeable $\mathrm{Ca}$ and $\mathrm{Mg}$ in soil were generally higher than those in control. Different concentration of A. niger XF-1 fermentation broth could increase the photosynthetic pigment content and the growth of A. fruticosa seedlings significantly.

SEM results showed that the root surface of $A$. fruticosa had a large number of metabolites and granites after inoculation of $A$. niger XF-1. It indicated that XF-1 could colonize on the granite and the root surface of A. fruticosa, produce a large number of mycelia and secrete metabolites. The granite weathering effect on A. fruticosa was obvious. This study provides a new idea for ecological restoration of degraded habitats and a new model for rapid soil formation and wall greening of exposed rocks in abandoned mining areas. At present, the use of microorganisms for ecological restoration is still in the experimental stage, and the effect of mountain slope greening remains to be further studied.

Acknowledgements. This research was supported by the positioning research project of Forest Ecosystem of Changjiang River Delta in Jiangsu Province, the Engineering Project 'Three New' for Forestry in Jiangsu Province (lysx [2013] 10), a project funded by the Priority Academic Program Development of Jiangsu Higher Education Institutions, the open project of the Key Laboratory of Soil and Water Conservation and Ecological Restoration in Jiangsu Province, and the Doctoral Research Fund Project of Anyang Institute of Technology (BSJ2020003).

\section{REFERENCES}

[1] Benoit, I., van den Esker, M., Patyshakuliyeva, A. et al. (2015): Bacillus subtilis attachment to Aspergillus niger hyphae results in mutually altered metabolism. Environmental Microbiology 17(6): 2099-2113.

[2] Bao, S. D. (1981): Soil Agrochemical Analysis. 3rd Ed. - China's Agricultural Publishing House Beijing.

[3] Cui, B. X., Zhang, X. X., Han, G. et al. (2016): Antioxidant defense response and growth reaction of Amorpha fruticosa seedlings in petroleum. - Contaminated Soil. Water, Air, \& Soil Pollution 227(4): 121.

[4] Eriola, V., Glenda, S., Astrit, B. (2018): Tripartite relationships in legume crops are plant-microorganism-specific and strongly influenced by salinity. - Agriculture 8(8): 117.

[5] Gong, M. B., Fan, B. Q., Jin, Z. G. et al. (2010): Screening and application of phosphatedissolving microorganism suitable for corn production. - Acta Microbiologica Sinica 50(12): 1619-1625.

[6] Huang, Y. H., Tang, R. S., Ye, X. Q., et al. (2009): Effect of ABA on the germination of white grain wheat seeds and growth of its seedlings. - Journal of Triticeae Crops 29(3): 503-507.

[7] Jiang, X. J., Huang, Z. X., Xie, D. T., et al. (2000): Promoting effects of the metabolites of silicate for plant growth. - Journal of Southwest Agricultural University 2(2): 116-119. 
[8] Li, M., Ma, Q. Q., Zhao, H. J., et al. (2012): Effect of micro-derived hardiness agent on endogenous hormones content in maize roots. - Heilongjiang Agricultural Sciences 29(8): 47-49.

[9] Li, S., Duan, Y. X., Zhu, X. F. et al. (2011): Effects of adding secondary metabolites of Aspergillus niger on resistance to tomato root-knot nematode. - China Vegetables 1(4): 44-49.

[10] Lü, J., Tian, X. H., Y, H. et al. (2015): Effect of Aspergillus niger fermentation liquid on the growth of wheat seedings in calcareous soil. - Journal of Northwest Agriculture and Forestry University (Natural Sciences Edition) 43(5): 100-106.

[11] Meena, V. S., Meena, S. K., Verma, J. P. et al. (2017): Plant beneficial rhizospheric microorganism (PBRM) strategies to improve nutrients use efficiency: a review. Ecological Engineering 107: 8-32.

[12] Qian, L. Z., Gong, M. B., Gu, J. G. et al. (2014): Effect of two different fungi on nutrient dynamic changes in soil. - Chinese Soil and Fertilizer 41(5): 86-89.

[13] Saxena, J., Rawat, J., Sanwal, P. (2016): Enhancement of growth and yield of glycine max plants with inoculation of phosphate solubilizing fungus Aspergillus Niger K7 and biochar amendment in soil. - Communications in Soil Science and Plant Analysis 47(20): 2334-2347.

[14] Wang, X. H., Wang, C. D., Sui, J. K. et al. (2018): Isolation and characterization of phosphofungi, and screening of their plant growth-promoting activities. - AMB Express 8(1): 63.

[15] Wang, Y. Q., Xu, H. L., Xu, G. Y. et al. (1993): The applicable of AP-2 Aspergillus niger dissolve phosphorus microorganism in the planting tobacco. - Biotechnology 3(1): 4-38.

[16] Wang, Y. X., Zhang, J. C., Wu, Y. W. et a1. (2017): Effects of soil bacteria inoculation in spray seeding matrix on photosynthesis characteristics and chlorophyll fluorescence parameters of Amorpha fruticose. - Research of Environmental Sciences 30(6): 902-910.

[17] Wu, Q. F., Hu, H. B., Zhang, X. (2018): Effect of Aspergillus niger and its metabolites on weathering of granite. - Journal of Nanjing Forestry University (Natural Sciences Edition) 42(1): 81-88 (in Chinese).

[18] Wu, Q. F., Hu, H. B. (2019): The influence of environmental factors on Aspergillus niger granite weathering. - Applied Ecology and Environmental Research 17(1): 395-408.

[19] Wu, Y. W., Zhang, J. C., Guo, X. P., et al. (2017a): Identification of efficient strain applied to mining rehabilitation and its rock corrosion mechanism: based on boosted regression tree analysis. - Environmental Science 38(1): 283-293 (in Chinese).

[20] Wu, Y. W., Zhang, J. C., Wang, L. J. et al. (2017b): A rock-weathering bacterium isolated from rock surface and its role in ecological restoration on exposed carbonate rocks. - Ecological Engineering 101(1): 162-169.

[21] Yan, W. M., Zheng, S. X., Zhong, Y. q. W. et al. (2017): Contrasting dynamics of leaf potential and gas exchange during progressive drought cycles and recovery in Amorpha fruticosa and Robinia pseudoacacia. - Scientific Reports 7(1): 4470.

[22] Yang, C. X. (2008): Amorpha fruticosa L. is a superior aforestation tree species in semiarid waste dump area. -Forestry Science and Technology information 4(03): 30-31.

[23] Zhang, J. (2004): Contrast determination of available $\mathrm{Cu}, \mathrm{Zn}, \mathrm{Fe}, \mathrm{Mn}$ in soil by DTPA and M3 extraction. - Journal of Shanxi Agricultural Sciences 32(3): 30-33.

[24] Zhang, L. Z., Fan, J. J., Niu, W. et al. (2011): Isolation of phosphate solubilizing fungus (Aspergillus niger) from Caragana rhizosphere and its potential for phosphate solubilization. - Acta Ecologica Sinica 31(24): 7571-7578.

[25] Zhong, W. Y., Shi, F. C., Hong, M. J. et al. (2015): Phosphate solubilization and promotion of maize growth by Penicillium oxalicum $\mathrm{P} 4$ and Aspergillus niger P85 in a calcareous soil. - Canadian Journal of Microbiology 61(12): 1-11. 